\title{
INEQUALITIES FROM GENERAL QUASI-LINEAR MEANS
}

\author{
STEPHEN G. WALKER
}

\begin{abstract}
The paper has a number of aims. The first is to demonstrate the use of the comparison theorem for quasi-linear means to see how mean inequalities, and other apparently unrelated inequalities, can be seen from the perspective of quasi-linear means. Second, we will be generalizing some means, such as the identric mean, by observing its representation as a quasi-linear mean. Finally, we will generalize the quasi-linear mean comparison theorem which provides an extension to the Jensen-Steffensen-Boas inequality for a strictly increasing concave function. This allows for new inequalities to be introduced.
\end{abstract}

Mathematics subject classification (2010): 26D15.

Keywords and phrases: Concave function; distribution function; Jensen-Steffensen inequality; NeymanPearson lemma.

\section{REFERENCES}

[1] S. Abramovich, G. FARId, S. IVelić And J. Pečarić, On exponential convexity, JensenSteffensen-Boas inequality, and Cauchy's means for superquadratic functions, J. Math. Inequal. 5 (2011), 169-180.

[2] H. Alzer, Some gamma function inequalities, Math. Comp. 60 (1993), 337-346.

[3] M. Bajraktarević, Sur une équation fonctionelle aux valuers moyennes, Glasnik Matematički Fizički i Astronomski 13 (1958), 243-248.

[4] N. BATIR, On some properties of digamma and polygamma functions, J. Math. Anal. Appl. 328 (2007), 452-465.

[5] N. Elezović And J. PeČArić, Differential and integral $f$-means and applications to digamma function, Math. Inequal. Appl. 3 (2000), 189-196.

[6] N. Elezović, C. Giordano And J. PeČArić, The best bounds in Gautschi's inequality, Math. Inequal. Appl. 3 (2000), 239-252.

[7] S. GAO, Inequalities for the Seiffert's means in terms of the identric mean, J. Math. Sci. Adv. Appl. 10 (2011) 23-31.

[8] W. GAUTSCHI, Some elementary inequalities relating to the gamma and incomplete gamma function, J. Math. Phys. 38 (1959), 77-81.

[9] G. H. Hardy, J. E. Littlewood and G. Pólya, Inequalities, Cambridge University Press, 1934.

[10] C. S. Hong, A generalization of the quasilinear mean with applications to the measurement of income inequality and decision theory resolving the Allais paradox, Econometrica 51 (1983), 1065-1092.

[11] J. MićIĆ, Z. PAVIĆ AND J. PEČARIĆ, The inequalities for quasi-arithmetic means, Abstr. Appl. Anal., Article ID 203145, 25 Pages, 2012.

[12] P. Muliere And G. Parmigiani, Utility and means in the 1930s, Statist. Sci. 8 91993), 421-432.

[13] J. NeYMAN AND E. S. PEARSON, On the problem of the most efficient tests of statistical hypotheses, Philos. Trans. R. Soc. Lond. Ser. A Math. Phys. Eng. Sci. 231 (1933), 289-337.

[14] J. W. PRATT, Risk aversion in the small and the large, Econometrica 32 (1964), 122-136.

[15] F. QI, S. GuO And S. X. CHEN, A new upper bound in the second Kershaw's double inequality and its generalizations, J. Comput. Appl. Math. 220 (2008) 111-118.

[16] Y. F. QIU, M. K. WAng, Y. M. Chu And G. D. WANG, Two sharp inequalities for Lehmer mean, identric mean and logarithmic mean J. Math. Inequal. 5 (2011), 301-306.

[17] W. RosenheInRICH, Tables of Some Indefinite Integrals of Bessel Functions, Report: University of Applied Sciences Jena, http://www.fh-jena.de/ rsh/Forschung/Stoer/besint.pdf. 
[18] H. Sun, B. Long AND Y. CHu, On the generalized weighted quasi-arithmetic integral mean, Int. J. Math. Anal. 7 (2013), 2039-2048. 